\section{Improving Indian universities}

SIR - The problems of Indian universities (Nature 366, 617; 1993) are much more complex than those experienced in Russia and elsewhere. What many Indian universities urgently need is better leadership and less political interference.

In many parts of India, teachers in junior colleges are better qualified than senior college (graduate and postgraduate level), teachers. To teach in a junior college, one needs a relevant postgraduate degree (MA, MSc, MCom) and a degree in teaching (BEd), whereas in senior college one needs only a postgraduate degree. If a teaching degree were an essential qualification, teachers would be much more effective. The national entrance test (NET) for eligibility for lecturership (assistant professorship) in the universities and colleges is not compulsory in some places, so there is no uniform standard in higher education. To improve college-level teaching, the government must make the NET and teachers' training compulsory at the senior college level. Around 1980, a research degree (MPhil/ $\mathrm{PhD}$ ) was made a prerequisite for annual increments in pay after eight years of service. For this a faculty improvement programme (FIP) was introduced by the University Grants Commission (UGC), and serving college teachers were given study leave to pursue a research degree. But this has not produced the desired results, perhaps because research experience in a narrow subject area is not what is needed for teaching at college level. The money spent on FIP could have been better used in improving facilities so that students completing research degrees could continue research at their own colleges. The UGC could draw up a fresh programme for library and laboratory improvements in the colleges, which would benefit both teachers and students. A shorter teacher-training programme could be introduced, incurring less expense and bringing a qualitative change.

Because of the shortage of funds, it is essential that available funds are used properly. A committed leadership would help enormously. There are nearly 50,000 unemployed PhDs in India, and what is needed is job oriented courses, vocational guidance and increased fees for college and university education. To avoid excluding children of poor parents from higher education, it would be sensible to increase fees to a quarter of the actual cost and to provide the present level of subsidy only to the genuinely deserving.

In India, teachers ('gurus') are traditionally respected next only to one's parents. That is one reason why many choose teaching as a career. The salary of a junior staff member in a university department is roughly US\$150 a month
( $\$ 75$ as basic pay and a similar amount as perks). A full professor may get roughly double that. (The figures are twice those reported in your article.) Difficulty in finding suitable accommodation is not the only reason why academics tend to stay where they are. India is a country of many languages and many cultures. Each state has its own language and culture. Those seeking jobs and those looking for suitable candidates probably have a bias towards people of similar background. The situation could be improved by making appointments at national level on the basis of a competitive examination (as is done with central civil service and bank jobs).

Universities need more autonomy, but it needs first to be established whether or not the autonomy enjoyed at present is properly used for academic growth. As long as universities are dependent on state governments for funds and there are no reliable and scientific methods for evaluating their performance, more autonomy may lead to more problems.

A distinction needs to be made between the academic and administrative functions of the universities. The examination departments should be brought under an administrative head and also under the consumer protection act to make them more efficient. A uniform standard at national level could be brought about by introducing a common syllabus and a common body for the coordination of examinations in all universities.

S. John

Shibu Nivas, Sagar Park,

S. No. 46/9 NagarRoad,

Pune 411014, India

\section{Animal welfare}

SIR - The five letters in the correspondence section (Nature 369, 9-10; 1994) concerned with Peter Singer's review of the books Monkey Business and In the Name of Science (Nature 367, 523; 1994) all serve as examples of the 'we/them' attitude that sadly characterizes the approach taken by many people interested in animal welfare.

Adrian R. Morrison wrote in a dispassionate manner about the limb injuries to two monkeys and claimed that they were "in otherwise good health", using criteria ("alert, well-fleshed and with gleaming hair coats") that in no obvious way indicate either good health or the absence of pain and suffering. Morrison also felt comfortable commenting on Singer's "inaccuracies and apparent lack of medical knowledge", supporting his claim by citing a paper by Sharon Russell and Charles Nicoll (Proc. Soc. exp. Biol. Med.; in the press), the purposes of which are to cast doubt on Singer's character, his position on animal welfare taken in his book Animal Liberation, and his citations or interpretations of a very small percentage of articles to which he refers in chapter two ("Tools For Research") of Animal Liberation. However, Morrison failed to point out (and perhaps did not know) that Russell and Nicoll revised their prepublication draft after discovering that they were in error about one of their major beliefs concerning Singer's intentions to mislead readers of his book, namely Singer's claims about statements made by Elizabeth Whelan, executive director of the American Council on Science and Health. Many of Russell and Nicoll's other concerns about Singer's character, his errors in citation and interpretation and his lack of medical knowledge are also questionable as is shown in Singer's response to their charges (Proc. Soc. exp. Biol. Med.; in the press). People are urged to read both papers carefully to develop an informed view of the nature of the continuing controversy between Russell and Nicoll and Singer, for there are two sides to all stories.

\section{Marc Bekoff}

Department of Environmental, Population and Organismic Biology,

University of Colorado,

Boulder, Colorado 80309-0334, USA

\section{Population growth}

SIR - Orrego, Marengo and Bull (Nature 370, 92; 1994) demolish most effectively the crude application to the present of the Malthusian hypothesis. They show convincingly that there is no significant negative correlation between population density and wealth per head.

Interesting as this is, it has little if any relevance to present concern about population growth. Indeed, the link between poverty and population growth is quite striking. In no OECD ('wealthy') country does the rate of increase per year of natural population exceed 1.1 per cent, and in most of them it is below 0.8 per cent. In most developing ('poor') countries it exceeds 2 per cent and in many is 3 per cent or more. The rapidly industrializing countries of East and South-East Asia, as also Argentina, Brazil and Chile, lie in the 1-2 per cent band.

Although such a correlation does not establish a causal link, it is worth noting the momentum of the growth rate of population. With rapidly increasing numbers, a high proportion of people are in the fertile age groups or younger. Even if family sizes were to shrink immediately to those common in OECD countries, therefore, high growth rates of the populations would persist for many years.

\section{Hermann Bond}

Churchill College, Cambridge CB3 ODS, UK 